\title{
In search of robust flood risk management alternatives for the Netherlands
}

\author{
F. Klijn ${ }^{1}$, J. M. Knoop ${ }^{2}$, W. Ligtvoet ${ }^{2}$, and M. J. P. Mens ${ }^{2}$ \\ ${ }^{1}$ Deltares, Delft Hydraulics, Delft, The Netherlands \\ ${ }^{2}$ PBL Netherlands Environmental Assessment Agency, Bilthoven, The Netherlands
}

Correspondence to: F. Klijn (frans.klijn@deltares.nl)

Received: 12 August 2011 - Revised: 6 February 2012 - Accepted: 2 April 2012 - Published: 16 May 2012

\begin{abstract}
The Netherlands' policy for flood risk management is being revised in view of a sustainable development against a background of climate change, sea level rise and increasing socio-economic vulnerability to floods. This calls for a thorough policy analysis, which can only be adequate when there is agreement about the "framing" of the problem and about the strategic alternatives that should be taken into account.

In support of this framing, we performed an exploratory policy analysis, applying future climate and socio-economic scenarios to account for the autonomous development of flood risks, and defined a number of different strategic alternatives for flood risk management at the national level. These alternatives, ranging from flood protection by brute force to reduction of the vulnerability by spatial planning only, were compared with continuation of the current policy on a number of criteria, comprising costs, the reduction of fatality risk and economic risk, and their robustness in relation to uncertainties.

We found that a change of policy away from conventional embankments towards gaining control over the flooding process by making the embankments unbreachable is attractive. By thus influencing exposure to flooding, the fatality risk can be effectively reduced at even lower net societal costs than by continuation of the present policy or by raising the protection standards where cost-effective.
\end{abstract}

\section{Introduction}

The Netherlands aims at revising its flood risk management policy for the 21st century (Ministry of Transport, Public Works and Water Management, 2009). Reasons for this are
- as in many other countries - an increasing attention for climate change and the resulting sea level rise and extreme river discharge increase, which increase the flood hazard, and the notion that the socio-economic vulnerability of the country also has increased and continues to increase. As for the latter, a number of reports and advice to the Netherlands' government drew attention to the fact that the Netherlands' standards for flood protection largely date from the 1960s, when they were proposed by the Delta Committee, and have not been updated since (Klijn et al., 2004a; Ten Brinke and Bannink, 2005; Ten Brinke et al., 2008). These standards were based on the then demographic and economic situation, but both the population and economy have grown substantially since then. Ten Brinke and Bannink (2005) therefore advised to regularly update the protection standards. This resulted in the government's initiative to strive for such an update ("Water Safety 21 st century", abbreviated as WV21), supported by dedicated research (Beckers and De Bruijn, 2011; De Bruijn and Van der Doef, 2011; Kind, 2011).

A number of flooding events in various parts of our climatic zone in the first decade of the 21st century (Elbe floods in Central Europe: 2002, 2006; UK: 2007, 2008; USA: 2005 (Katrina)) alerted authorities and organizations in the Netherlands, also beyond the responsible ministry (of Transport, Public Works and Water Management). This resulted in the installation of a 2nd Delta Committee. This committee reported in 2008 and advised, among other things, to raise the "safety level" to at least a factor 10 . This was generally interpreted as a call to raise the flood protection standards - which according to current law ranges from 1:250 to $1: 10000$ per year - with a factor 10 . As this would require huge investments in embankments, and interfered with the already begun research on revising the flood protection

Published by Copernicus Publications on behalf of the European Geosciences Union. 
standards, the advice was answered by a national water plan (Ministry of Transport, Public Works and Water Management, 2009), which - again among many other things - proposed a three-layered flood risk management policy. This distinguishes between flood defence as first layer and keystone, supplemented by "sustainable spatial development", and disaster management as second and third layers.

The first step of this policy involves the already begun revision of the protection standards. But following the advice of the committee, it was decided that these standards were to be based not only on economic cost-benefit analysis (Eijgenraam, 2006; Messner et al., 2007; Kind, 2008), but also on considerations about acceptable fatality risk, more specifically on local individual risk and group risk (or "collective" risk). This approach to defining flood protection standards can be qualified as risk-based and state-of-the-art (cf. FLOODsite, 2009).

However, also protection standards that are revised on a risk-based approach still only rely on flood defence as the prime means to reduce flood risk. And fully relying on flood defence may not be the most cost-effective or most attractive flood risk management strategy, as pointed out by, e.g., Klijn et al. (2007), De Bruijn et al. (2008) and Ligtvoet et al. (2009). Most importantly, this proposed policy does not start from a comprehensive flood risk management approach as it is advocated by the EU-Integrated Project FLOODsite (2009; cf. also Schanze, 2006). A comprehensive approach should equally take into account measures aimed at (1) reducing flood probability, (2) reducing exposure to floods and (3) reducing the vulnerability of people and property, and treat these as equivalent and mutually exchangeable (Klijn et al., 2008).

Against this background, we addressed the question of which strategic policy for flood risk management might be the most attractive for the Netherlands in the 21st century (Klijn et al., 2010), in the sense that it would reduce the risk to a societally acceptable level against acceptable costs. We did so by performing an exploratory policy analysis, which involved the comparison of remaining flood risks and costs of a number of strategic alternatives. The alternatives comprise increasing the protection level with factor 10 , as advocated by the 2nd Delta Committee (2008), and increasing the protection level where cost-effective, but also alternatives that rely partly or fully on the reduction of exposure to great water depths or high flow rates or on the reduction of the vulnerability of people and property. The current policy, which is already adaptive to some degree (cf. Klijn et al., 2012), serves as a reference.

In this paper we shall first explain the procedure we followed, which can be qualified as an exploratory policy analysis or a "rapid prototyping" of a policy analysis. Its main purpose was to influence the framing of the problem and of the strategic alternatives that deserve being taken into account, i.e. the framing as shared by the responsible policy makers and their advisors, who jointly decide on what to investigate.

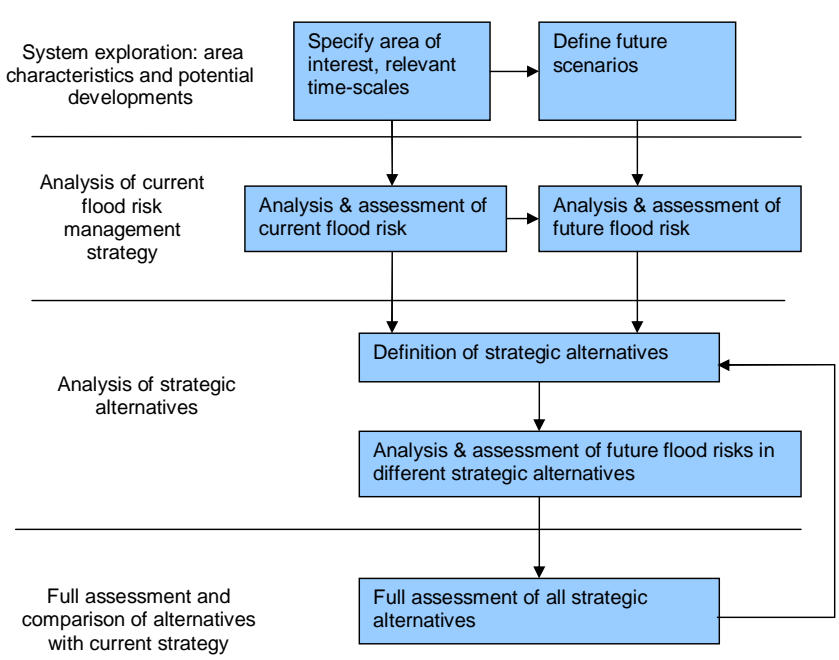

Fig. 1. Procedure (steps and tasks) for an exploratory policy analysis in behalf of long-term flood risk management planning (after De Bruijn et al., 2008).

Next, we go into the strategic alternatives we distinguished, followed by an assessment and discussion on their advantages and disadvantages. We round off with a reflection on the approach.

\section{An exploratory policy analysis: the procedure}

Policy analysis can be interpreted in two ways: as an analysis of actual policy or as an analysis in behalf of planning and policymaking (Thissen, 1997; Walker, 2000). We follow the second interpretation, after a first and very satisfactory application for the Netherlands' water management by the RAND Corporation (Pulles, 1985; Walker, 1986). It requires following a stepwise procedure, which we adapted from a general "framework" for the purpose of long-term flood risk management planning (De Bruijn et al., 2008). Figure 1 depicts this procedure, which consists of a number of stages.

The analysis starts by defining the focal system and the focal problem. In our case it refers to the flood risk system of the Netherlands, which is geographically determined by the flood-prone area and conceptually by a combined geoecosystem and socio-economic subsystem. This system is best characterized by those factors that - apart from the hazard - jointly determine flood risk: relief and (flood defence) infrastructure, which together determine exposure; and people (population and economic activity) and property (including land use), whose behaviour and characteristics determine vulnerability to flooding. The focal problem is the present flood risk, but perhaps even more importantly, the future flood risk.

For the Netherlands, the flood risk system comes down to 53 main dike-ring areas that are protected by flood defences, and unprotected floodplain area along the main rivers, 
estuaries and coast. We focus on the dike-ring areas, as the flood risk in the unprotected floodplains is small in comparison to that in the protected areas, thanks to the legal framework prohibiting floodplain development and subjecting any exceptions to rigorous building requirements.

A first step in the analysis is the quantification of the flood risk in the present situation and in the future, under autonomous development. As the autonomous development cannot be known, but is instead highly uncertain, it is common practice to either use prognoses (best guesses), or to explore various futures by distinguishing scenarios (Veeneklaas and Van den Berg, 1995; Bertrand et al., 1999; Van Asselt et al., 2001; UKCIP, 2002; UNEP and RIVM, 2003; Popper et al., 2005). The latter approach has advantages as it allows establishing which alternative strategy performs adequately in different possible circumstances. Performing adequately here means that the strategy is perhaps not the best in one scenario, but does not perform very poorly in other future scenarios either, e.g. by resulting in high risk or huge costs. Such a strategy can hence be regarded as being relatively insensitive to uncertainty about future external developments (Popper et al., 2005; Haasnoot et al., 2011).

A first alternative to assess is usually to "do nothing". This is commonly called the zero-alternative. But as the Netherlands already has an adaptive flood risk management policy in place (cf. Klijn et al., 2012), doing nothing is no realistic option, as it does not comply with the Water Law that is currently in force. The current Netherlands' policy involves at least a 6-yr update of the design conditions and - when needed - the subsequent raising or reinforcement of the embankments. This implies that for reference purposes we need to assume the continuation of the current policy and practice, and establish the change in flood risk under various scenarios. The results of this analysis have been reported by Klijn et al. (2012).

Alternatives for the current policy may comprise other measures and policy instruments to reduce flood risk. There are many different measures and policy instruments available, which may be combined in many different ways in many different locations. Therefore, De Bruijn et al. (2008; FLOODsite, 2009) advocated to combine them into a surveyable number of strategic alternatives. Four to six alternatives seems to be a practicable number, which allows sufficiently thorough analyses and still easy interpretation. In this context, strategic alternatives are defined as coherent sets of flood risk management measures and related policy instruments (FLOODsite, 2009). Measures and instruments may reduce flood probabilities or, alternatively, flood impacts. In practice, technical measures are usually considered first, after which regulatory, financial and communicative instruments are added (De Bruijn et al., 2008). The review we did in FLOODsite made us propose a top-down approach for defining strategic alternatives based on guiding principles, for example derived from "world-views" (related to "perspectives" as recognized by Thompson, 2002; cf. Van Asselt et al.,
2001; Haasnoot et al., 2011) or by deriving them from concepts such as resilience and resistance (Klijn et al., 2004b; De Bruijn, 2005). We applied the second option, as we explain in the next section.

The next step is to assess the various strategic alternatives and to compare them with the reference alternative. This means a confrontation of all the strategic alternatives with the possible future scenarios. Such a confrontation enables us to assess (1) what the best strategic alternative is under one given scenario, and (2) how the various strategic alternatives perform under various scenarios.

As flood risk management is no goal in itself, but instead should contribute to the sustainable development of regions, such an assessment should preferably relate to the three domains (or realms) of sustainable development: social equity, ecological integrity, and economic efficiency. This is often addressed as the triple-P concept: People, Planet and Profit. De Bruijn et al. (2008) advised to add the criteria robustness and flexibility to these sustainability criteria in order to cover the issue of "coping with uncertainty", an interesting suggestion that deserves further consideration. We come back to this issue in our discussion. We prefer to call this full assessment a sustainability assessment, but others would address it as a societal cost-benefit analysis, which takes into account all costs and benefits to society, whether monetary or not.

In our study on strategic alternatives for the Netherlands flood risk management policy, we followed this procedure, which Fig. 1 depicts as a linear process. We do recognize that management planning in practice is, of course, a cyclic process (Hutter et al., 2007). Various iterations between alternative design and analysis are therefore likely, and even within one iteration alternatives may be adapted when unfavourable results are obtained, or additional alternatives may be added halfway. We consider our studies as some first, and still quite coarse iterations, for Klijn et al. (2007) performed a first exploration only, without any iteration at all, whereas Klijn et al. (2010) already considered better-defined alternatives, which are more realistic in the sense that they apply measures commonly regarded as feasible and acceptable. In comparison to a full-fledged policy analysis, our approach would however classify as merely an exploratory policy analysis or a "rapid prototype".

This, however, afforded us to take a helicopter-view of the whole issue of flood risk management planning for the very long term. For strategic planning at the national level, this has obvious advantages, as it prevents dwelling on details and thus may yield relevant new insights. The main purpose of our study was to contribute to a more comprehensive framing of the problem at the national scale, of its precise character and location, as well as of the strategic alternatives and the measures and instruments that deserve being taken into account. 
Table 1. Examples of flood risk reducing measures (after Klijn and De Grave, 2008) that were incorporated in the strategic alternatives.

\begin{tabular}{lll}
\hline & Preventive Flood Risk Management & Flood Event Management \\
\hline Reduction of flooding probability & Implementing and/or raising embankments & Sand bags against overtopping \\
& Increasing the sand volume in dunes & Temporary reinforcement of weak spots \\
& Storm surge barriers & Immediate repair of imminent breaches \\
& River training and room for rivers & Small frequent coastal sand nourish- \\
& Large coastal sand nourishment schemes & ment \\
Consequence reduction & Compartmentalization & Evacuation (horizontal and vertical) \\
(exposure and vulnerability) & Unbreachable embankments & Transport of goods to safe havens \\
& Overflow sills & \\
& Risk zoning and building regulations & \\
\hline
\end{tabular}

\section{Strategic alternatives for flood risk management}

Flood risk management can be considered as a significant evolution of flood management (Samuels et al., 2006), which recognizes that one should not manage the flood, but instead the risk (Klijn et al., 2008). This means that one should equally consider measures that influence the flood hazard and measures that reduce society's vulnerability. In the Netherlands' institutional context, this translates into technical water management measures, which primarily aim at reducing the flood probability, and spatial planning measures, which aim at lowering the consequences by reducing the exposure of people and property as well as their vulnerability (Table 1). The technical measures are usually implemented by water management authorities, such as the national Rijkswaterstaat and the regional water boards, whereas the "non-structural" policy instruments aim at third parties (Hutter et al., 2008), requiring them to reduce their exposure and/or vulnerability. The authorities may try to convince these third parties, persuade them by means of financial incentives, or simply enforce legal regulations (FLOODsite, 2009).

We developed five strategic alternatives for comparison with the continuation of the current flood risk management policy (Table 2). These rely on different combinations of flood defence and control on the one hand (vertical axis in Table 2) and spatial planning measures on the other (horizontal axis). They can thus also be regarded as different mixtures of resistance-increasing and resilience-increasing measures. The resistance is increased when the protection against being flooded is further improved, whereas the resilience is increased when the capacity to cope with and restore from flooding is enhanced. Alternatives 1 and 2 apply flood defence as the only measure, alternative 5 prevents all new development in flood-prone areas, and alternatives 3 and 4 apply technical measures to reduce the exposure to floods, without (3) or with (4) spatial planning. The alternatives thus correspond to different guiding principles.

Alternative 1 is a development from the current policy, constituted by raising the protection level where this is economically feasible, and by improving the embankments ac- cordingly. This was estimated to apply to 12 of the 53 dikering areas (Klijn et al., 2007), an estimate that was confirmed by later - more accurate - cost-benefit analyses (Kind, 2008, 2011). For the remainder of the dike-ring areas, the protection level is maintained at the present level, as lowering it might meet with massive opposition for reasons of "unacceptable inequality". This alternative is thus quite realistic in the sense that it resembles the policy change that was announced in the Netherlands' National Water Plan of 2009, although our alternative relies primarily on economic costbenefit reasoning and does not take into account fatality risk.

Alternative 2 is a bit of a simplistic interpretation, in particular of the advice of the 2nd Delta Committee (2008), who argued that the "water safety" should be improved by a factor 10. We interpreted "water safety" as the flip side of flood risk and its improvement as a plea for raised protection standards. Accordingly, we assumed that the flood defences protecting all 53 dike-ring areas are raised to such an extent as to reduce the flooding probability by a factor 10 , but applying conventional embankments that may breach when overloaded. This alternative involves the improvement of some $3000 \mathrm{~km}$ of flood defences, and raising their crest height with another $0.3 \mathrm{~m}$ to more than $2 \mathrm{~m}$, depending on location and hazard type (sea, lake or river). Although we, of course, admit that another interpretation of the committee's advice is possible, it is illustrative to include this extreme alternative in the comparison.

In another alternative (5) we explored which risk reduction might be achieved by spatial planning only. Klijn et al. (2012) already showed to what extent demographic and economic development in the Netherlands influence the development of flood risk over time. This alternative 5 is founded upon the notion that without people and urban development, there is no risk (FLOODsite, 2009), which is translated into a policy that deliberately locates all new developments from 2010 onwards outside the flood-prone area. This alternative thus reveals (some of) the costs and benefits of careful spatial planning, more specifically the potential contribution of spatial planning in reducing future flood risks. 
Table 2. The investigated strategic alternatives, as combinations of measures from water policy (flood defence, flood control; vertical axis) and from spatial policy (zoning, regulatory measures; horizontal axis).

\begin{tabular}{|c|c|c|c|c|}
\hline $\begin{array}{l}\text { Spatial policy } \\
\text { (non-structural) } \\
\text { Water policy/ structures }\end{array}$ & $\begin{array}{l}\text { Autonomous } \\
\text { (no dedicated } \\
\text { policy) }\end{array}$ & $\begin{array}{l}\text { Zoning and building } \\
\text { regulations }\end{array}$ & $\begin{array}{l}\text { Differentiated } \\
\text { guided development }\end{array}$ & $\begin{array}{l}\text { No development in } \\
\text { dike-ring areas }\end{array}$ \\
\hline $\begin{array}{l}\text { Brute force/ factor } 10 \\
\text { (flood defense) }\end{array}$ & $\begin{array}{l}2 \\
\text { Protect by } \\
\text { brute force }\end{array}$ & & & \\
\hline $\begin{array}{l}\text { Extra protection } \\
\text { if } \mathrm{B} / \mathrm{C}>1 \\
\text { (flood defense) }\end{array}$ & $\begin{array}{l}1 \\
\text { Better protect where } \\
\text { cost-effective }\end{array}$ & & & \\
\hline $\begin{array}{l}\text { Present } \\
\text { policy and practice } \\
\text { (legal 6-yearly update) }\end{array}$ & $\begin{array}{l}0 \\
\text { Continuation of the } \\
\text { current policy }\end{array}$ & & & $\begin{array}{l}5 \\
\text { Retreat } \\
\text { from the flood-prone } \\
\text { area }\end{array}$ \\
\hline $\begin{array}{l}\text { Present policy + unbreachable } \\
\text { embankments at risky places }\end{array}$ & & $\begin{array}{l}3 \\
\text { Adapt upwards } \\
\text { by unbreachable } \\
\text { embankments }\end{array}$ & & \\
\hline $\begin{array}{l}\text { Room for water } \\
\text { (compartimentalization/unbreachable } \\
\text { overflow sills) }\end{array}$ & & & $\begin{array}{l}4 \\
\text { Accommodate and } \\
\text { living with water }\end{array}$ & \\
\hline
\end{tabular}

Alternatives 3 and 4 first aim at preventing the breaching of embankments, as this effectively reduces the amount of water flowing in and hence the exposure characteristics (Fig. 2). Both the extent of the flood and the water depths attained are thus much smaller. In alternative 3 we apply unbreachable embankments (cf. Silva and Van Velzen, 2008) over a significant length of the primary flood defences, at least along the Rhine and Meuse Rivers, as these know prolonged floods with high water levels lasting several days. Unbreachable embankments are defined as flood defences that are so strong that they can survive prolonged and massive overtopping without eroding away or being undercut from behind or below, which would result in structural failure and uncontrollable breaching. Especially in inclined dike-ring areas, such as the protected alluvial plains along the Rhine River, breaching may result in huge masses of water flowing into a dike-ring area. The large rivers thus already account for $1400 \mathrm{~km}$ of embankments to transform. Further, unbreachable embankments are applied at risky places (De Bruijn and Klijn, 2009; Fig. 3), where the warning time is short and evacuation difficult. This adds some 50 to $100 \mathrm{~km}$ of stretches of unbreachable embankments along the coast, estuaries and Lake IJssel. All in all, in alternative 3 about half the length of the embankments is transformed (almost 1500 out of $3000 \mathrm{~km}$ ), affecting 35 of the 53 dike-ring areas.
Whereas alternative 3 still aims to equally protect all areas and at the same time reduce the inflow volumes, alternative 4 seeks to gain more control over the flooding pattern and process (Klijn et al., 2007, 2010; Ligtvoet et al., 2009). It predefines the location of inflow - by building overflow sills, as applied in France along the Loire (Klijn et al., 2008) as well as the order of flooding of different dike-ring areas - by differentiating the sill heights. This applies to 24 of the 53 dike-ring areas, all threatened by floods from rivers or lakes, as it requires that the whole system behaviour be controlled (Van Mierlo et al., 2007). The inflow volumes are controlled by preventing breaching of the defences: at the sill by sound construction, elsewhere by preventing the further rise of the water level through releasing the water pressure. And finally, the flood extent is limited by splitting-up four large dike-ring areas, where consequences may be effectively reduced by compartmentalization (Klijn et al., 2010). This alternative can thus be understood as being founded on the certainty of uncertainty, as it aims to gain some degree of control over floods of whatever magnitude. It does so by deliberately allowing flooding, but in the least vulnerable areas only. By predefining the order of flooding, any spatial development can be adapted to the flooding frequency that is attained. Development and building are promoted to be pursued either elsewhere or - when in a dike-ring area - otherwise. 

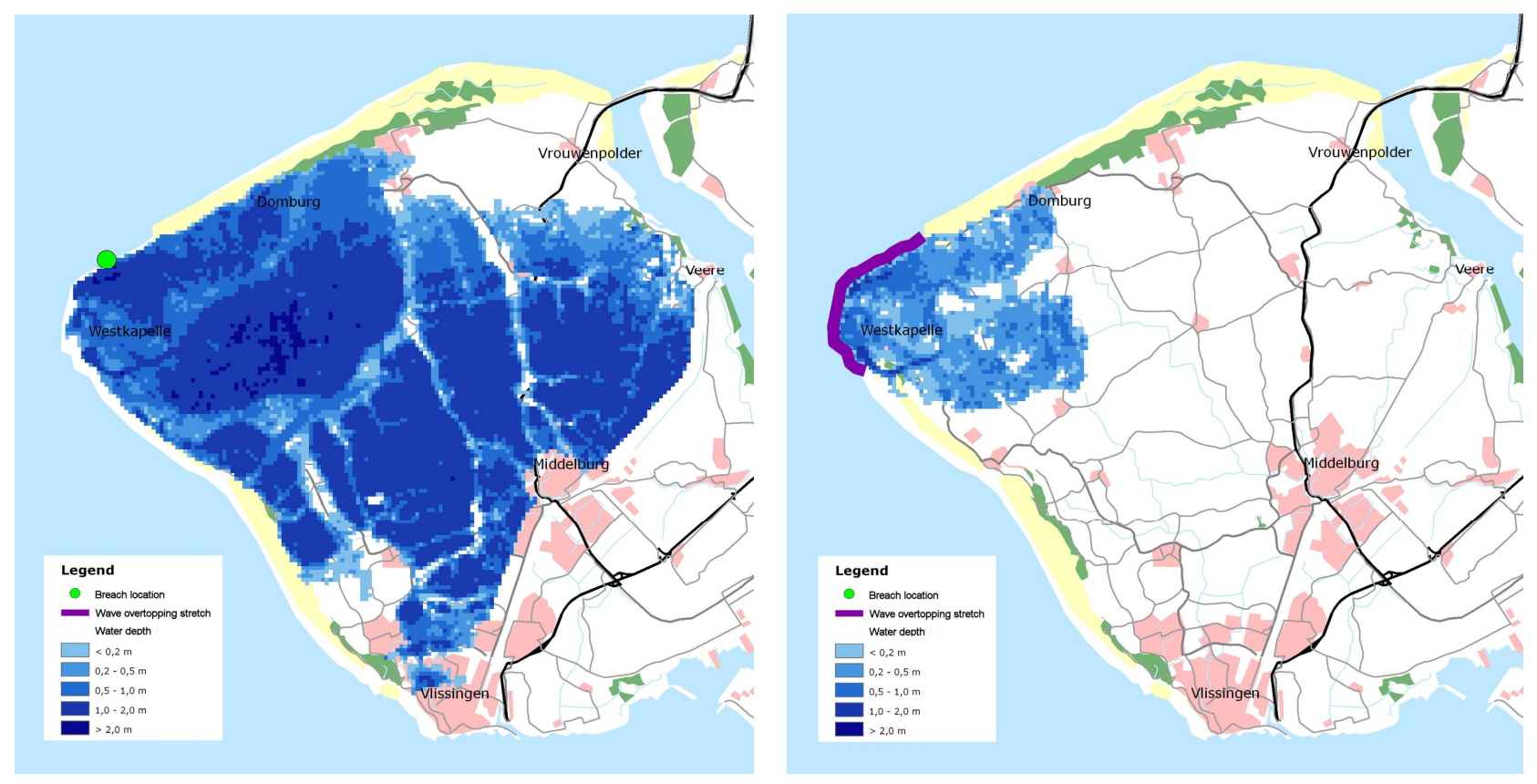

Fig. 2. Water depth resulting from a breach in conventional embankments (left), respectively from the overtopping of unbreachable embankments (right) as simulated for Walcheren (from Stijnen, 2008).

As a reference, we took the continuation of the current policy, which Klijn et al. (2012) already described and evaluated.

\section{Assessment of consequences and costs}

For each strategic alternative, we quantified the resulting economic risk and fatality risk, as well as the costs of its implementation and maintenance. We did so for 2050 , firstly, because the study aims at identifying the most attractive longterm policy for the 21 st century and, secondly, because the implementation of a new policy takes many decades - certainly when thousands of kilometres of embankments must be raised or reinforced. We also assume that a new strategy will not be implemented before 2015-2020, as the country is still in the middle of catching up with the backlog of reinforcing embankments that do not meet the current protection standards yet, and needs to decide on a possible change of strategy first.

We quantified the risks by - for each dike-ring area specifying flood probabilities, quantifying mean yearly economic damages and quantifying the mean annual number of fatalities. Economic damage and number of fatalities were estimated on the base of earlier calculations with the national standard model (HIS-SSM), but corrected for improved insight in likely flooding patterns as gained from a large number of flood simulations (Klijn et al., 2004a; see Klijn et al., 2012 for more elaborate treatment and examples). For the current policy the risks were assessed for
2005, 2020 and 2050, for the alternatives only for 2050. For 2050 we assumed a sea level rise of $15-35 \mathrm{~cm}$ and an increase of the Rhine River's design discharge from the present $16000 \mathrm{~m}^{3} \mathrm{~s}^{-1}$ to between $16500-17000 \mathrm{~m}^{3} \mathrm{~s}^{-1}$, as well as an average annual economic growth of $1.7 \%$ per head for a population, which will reach slightly more than 17 million inhabitants in 2050. In this paper, we do not go into the differences caused by different scenarios for future development, as Klijn et al. (2012) already reported about this. For the preliminary assessment in question, it is justified to look at one scenario only, as we are still in the stage of discovering the attractiveness of very different alternatives and individual measures. In a later stage, a full assessment for various future scenarios is recommended, however, as exemplified by De Bruijn et al. (2008). For the alternatives, we, of course, changed the flood probabilities and consequences according to the management measures taken.

Figure 4 shows the fatality risk in 2050 with all the alternatives, in comparison to the present risk and the risk in 2020 and 2050 as it would develop autonomously under current policy. The fatality risk is expressed as mean annual number of fatalities, which does correspond to large numbers during very rare events only. By 2020 the risk diminishes because of improvements to the flood defences and the making of room for rivers. Between 2020 and 2050 the risk rises somewhat because of population increase, but this is limited.

When we compare the alternative policies to the continuation of the current policy, we see that with brute force (2) the risk is reduced by $90 \%$, simply by decreasing the flood probability by factor 10 , but at substantial costs, as 


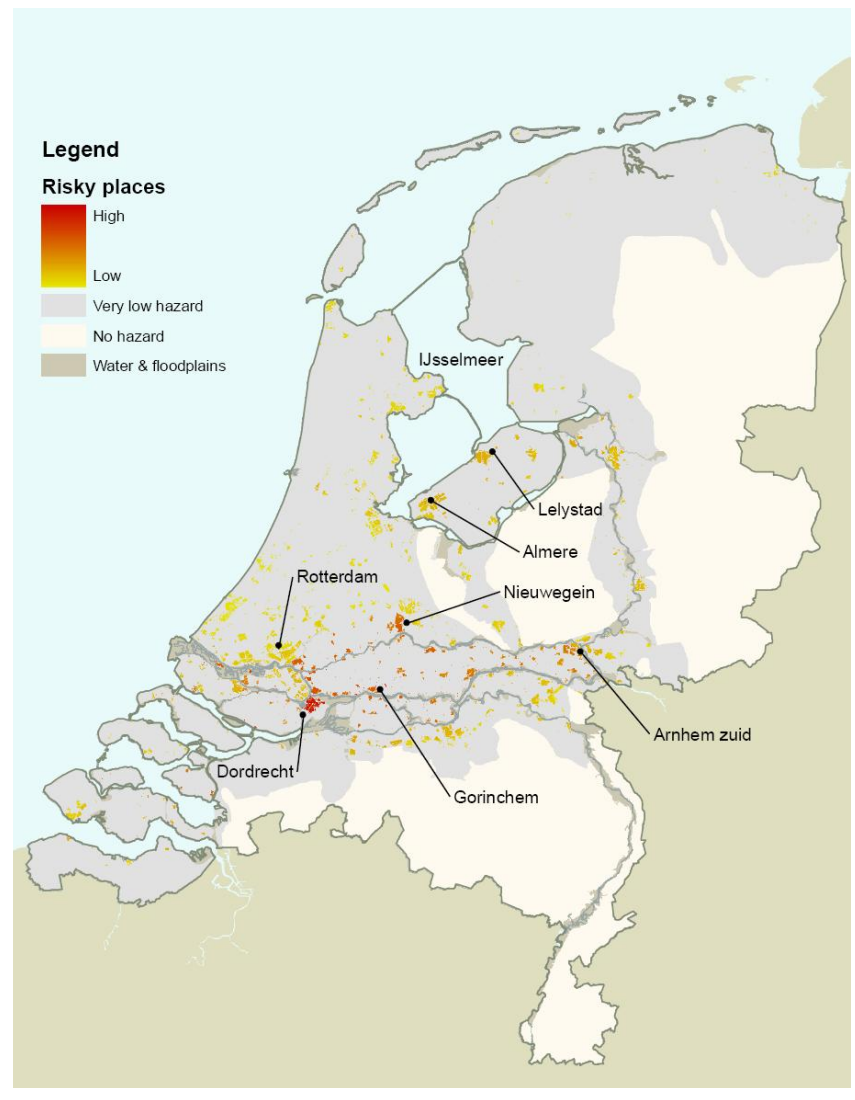

Fig. 3. At "risky places" unbreachable embankments may be very effective in reducing the risk of loss of life (De Bruijn and Klijn, 2009).

we will discuss below. Cost-effective protection $(1$, protect $)$ can reduce the fatality risk by more than $20 \%$, whereas $r e$ treat (5), which prevents new settlement in flood-prone areas, achieves somewhat less than $20 \%$ reduction. Effective reduction of fatality risk is also achieved by alternative 3 (adapts upwards) thanks to the unbreachable embankments, which reduce a flood disaster to a shallow flooding, and by alternative 4 (accommodate), with its differentiated flood control and defence system of inflow sills and compartmentalization, combined with spatial planning to reduce the vulnerability. These alternatives reduce fatality risk by $75 \%$, respectively $70 \%$.

Similar results are found for the economic damage risk (Fig. 5), but with some remarkable differences. Because economy keeps growing, and much faster than the population, the risk rises significantly between 2020 and 2050 under current policy. This also explains why the economic risk in alternative retreat (5) is higher than in 2020; even if no or little new development takes place, the existing property steadily increases in value with economic growth. With brute force (2) the economic risk can again be reduced by $90 \%$ in comparison to current policy, and by changing towards costeffective protection (alternative 1), the risk can be maintained

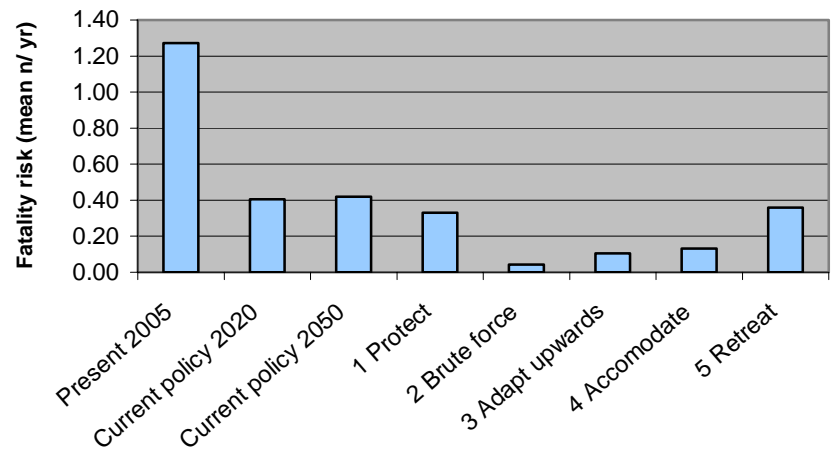

Fig. 4. Fatality risk (mean annual number of fatalities) in the various strategic alternatives in 2050, in comparison to the development of the risk between 2005 and 2050, assuming continuation of the current policy.

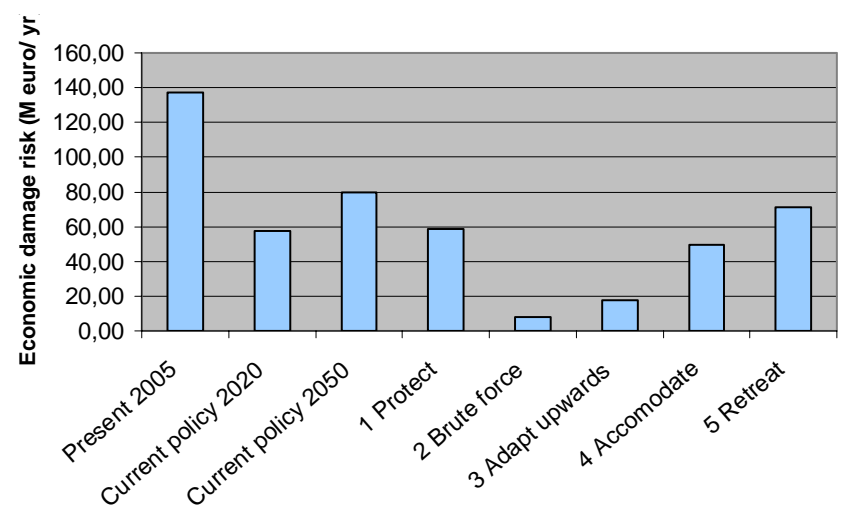

Fig. 5. Economic damage risk (mean annual damage) in the various strategic alternatives in 2050, in comparison to the development of the risk between 2005 and 2050, assuming continuation of the current policy.

at the 2020 level, some $30 \%$ lower than if the current policy were continued. Unbreachable embankments (3) or inflow sills with compartmentalization and associated spatial planning (4) both perform significantly better in reducing economic risk than present policy, but their effect is not as outstanding as it is in reducing fatality risk. That is because unbreachable embankments or overflow sills provide ample opportunity for evacuation or fleeing, which reduces the fatality risk very effectively, whereas the slow water level rise and the shallow maximum water depths attained also cause mortality rates to be much lower (Jonkman, 2007).

In Fig. 6 the geographical distribution of economic damage risk is shown for the 53 dike-ring areas for 2050; example maps are given for four distinct strategic alternatives. The figure shows that current policy (map a) sustains large spatial differences in economic risk, caused by a not very close relationship between flood protection standards and consequences of flooding. This leads to relatively high risks along the rivers - where the protection level is 1:1250 per year - in 


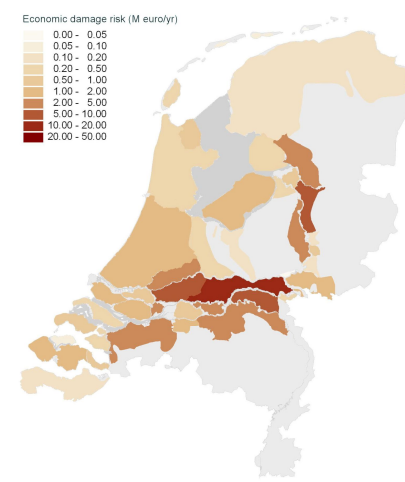

a

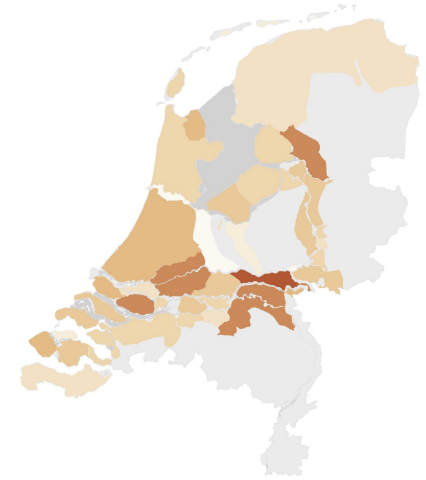

C

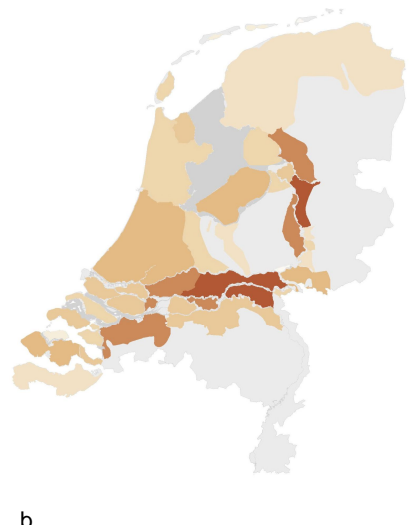

b

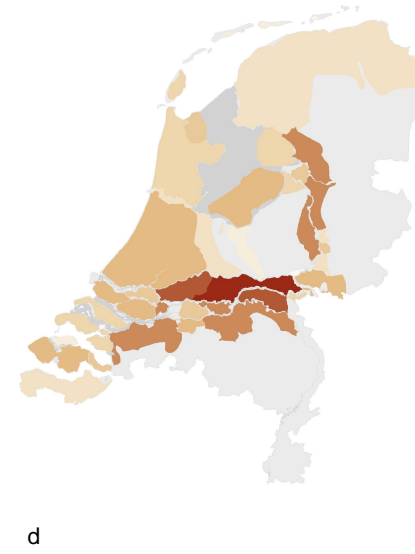

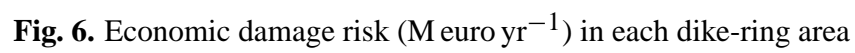
in 2050 if (a) the current policy were continued, and in various strategic alternatives: (b) "protect", (c) "accommodate" and (d) "retreat".

comparison to the coast - where the protection level ranges from 1:4000 to 1:10000. Brute force would yield a similar map, only faded to $10 \%$ of the values in map $6 \mathrm{a}$. By cost-effective protection (b), the spatial differences become slightly less and the same is true for retreat (map d). The most equal distribution of economic risk is achieved by alternative 4 (accommodate), which aims at differentiating the flood probabilities in relation to the vulnerability of the area, whilst at the same time gaining control over the flooding order and severity.

From these results it is obvious that flood risks can be effectively further reduced, both for people and the economy, but the benefits of each policy also meet with costs for implementation and maintenance. Even the present policy brings additional costs, as it is adaptive and requires that the embankments be raised with rising design water levels, apart from the usual yearly maintenance costs for the present defence system. We estimated the additional costs of implementation of the strategic alternatives, also for the continuation of the current policy, and included the extra maintenance costs. Thus, we derived annual costs for each policy alternative, which allows comparison. Table 3 summarizes the

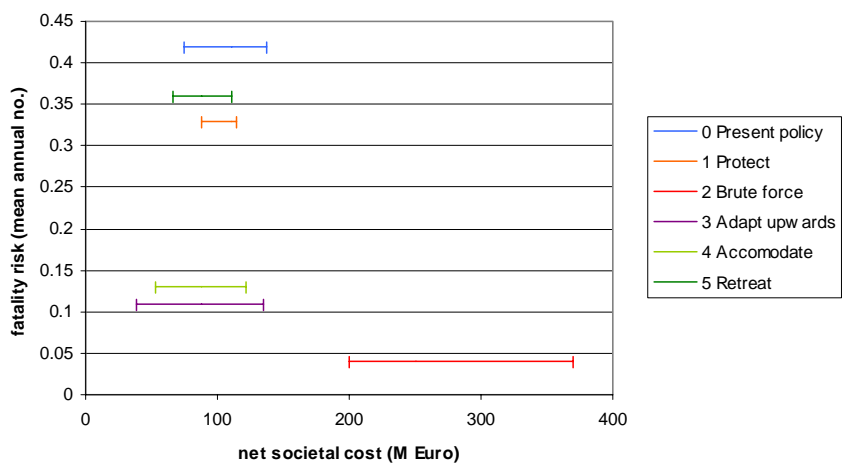

Fig. 7. Fatality risk as a function of net societal cost of each strategic alternative, with an indication of uncertainty about the precise annual societal costs (= implementation + maintenance + remaining economic risk) indicated by the "range" over the horizontal axis.

annual costs of implementing and maintaining each strategic alternative in the period 2020 to 2050 , as well as the remaining annual economic risks in 2050. The two figures add up to net annual societal costs. The table also shows the reduction in fatality risks, which we did not want to express in monetary terms.

In Fig. 7 we show the two criteria in relation to each other, as an aid to an overall assessment. The figure shows that continuation of the present policy (0) is not a bad policy at all, with already very low fatality risks and low net societal cost. By not allowing new developments in flood-prone areas (5 "retreat"), the fatality risk can be slightly lowered, as well as the net societal costs. Also by improving the flood defence in dike-ring areas where this is cost-effective (1 "protect"), a small but significant risk reduction can be achieved. Investing in a factor 10 better flood defence ( 2 "brute force") reduces the relative fatality risk of floods very much, but at high costs. In absolute terms it would correspond to less than one life saved per year - even if we account for a gross underestimate of fatality risk - with a societal cost of at least 50 million euros per year. This appears to be an "expensive" flood risk management policy, especially when we compare it with a justifiable value of a statistical life (VOSL) of about 6.7 million euros, as proposed by Bočkarjova et al. (2009). The strategies "adapt upwards" (3) and "accommodate" (4) achieve very significant reductions in the fatality risk at societal costs that are equal or even slightly lower than the costs of the current policy. The unbreachable embankments of "adapt upwards" require huge investments, but with a good return on investment in terms of effectively reduced economic risk. In the strategic alternative "accommodate", the initial investment is much less, but it requires acceptance of the increased economic risk related to more frequent though shallower - inundations in the least vulnerable areas. 
Table 3. Costs of the strategic alternatives and their effect in terms of change of risk, comparing strategy in place (=2050) with "system in order" (=2020).

\begin{tabular}{|c|c|c|c|c|c|c|c|c|c|c|c|c|}
\hline \multirow[b]{2}{*}{ Annual costs 1} & \multicolumn{2}{|c|}{$\begin{array}{c}0 \\
\text { Current policy }\end{array}$} & \multicolumn{2}{|c|}{$\begin{array}{c}1 \\
\text { Protect }\end{array}$} & \multicolumn{2}{|c|}{$\begin{array}{c}2 \\
\text { Brute force }\end{array}$} & \multicolumn{2}{|c|}{$\begin{array}{c}3 \\
\text { Adapt upwards }\end{array}$} & \multicolumn{2}{|c|}{$\begin{array}{c}4 \\
\text { Accommodate }\end{array}$} & \multicolumn{2}{|c|}{$\begin{array}{c}5 \\
\text { Retreat }\end{array}$} \\
\hline & 53 & 70 & 88 & 105 & 350 & 420 & 158 & 175 & 112 & 130 & 53 & 70 \\
\hline Change of annual damage risk & +22 & +67 & +1 & +10 & -50 & -150 & -40 & -118 & -8 & -59 & +14 & +41 \\
\hline Net mean annual costs $\left(\mathrm{M} € \mathrm{yr}^{-1}\right)$ & 75 & 137 & 88 & 115 & 200 & 370 & 39 & 135 & 53 & 122 & 66 & 111 \\
\hline Change of fatality risk (no $\mathrm{yr}^{-1}$ ) & \multicolumn{2}{|c|}{+0.01} & \multicolumn{2}{|c|}{-0.08} & \multicolumn{2}{|c|}{-0.36} & \multicolumn{2}{|c|}{-0.30} & \multicolumn{2}{|c|}{-0.27} & \multicolumn{2}{|c|}{-0.05} \\
\hline
\end{tabular}

Annual costs are assumed to amount $3.5 \%$ of the investment costs.

\section{Discussion on the results}

In this paper, we predominantly focused on implementation costs and benefits in terms of reduced risks. Any change of policy requires huge investments to be made, but so does a continuation of the present policy, because climate change and socio-economic development would otherwise result in an unacceptable increase of flood risks. It these circumstances - and given the general macro-economic situation it is likely that the availability of funds may become decisive for any decision on an alternative flood risk management strategy in the Netherlands.

However, there may be more criteria relevant in the background. For example, a further differentiation of flood protection levels, as in alternative 4 (accommodate), may meet with massive opposition from those inhabitants who feel negatively affected by such a policy, when their protection level is lowered. From the standpoint of policy makers, however, the possibility of a disaster with large numbers of people losing their lives may be more of a concern. Preventing such a disaster requires gaining control over the flooding process by - wherever possible - preventing breaches from forming and providing ample opportunity for evacuation. These additional rational considerations sometimes conflict with each other in their implications.

Next, the concept of "robustness" may become a relevant new assessment criterion in view of the inherent uncertainties related to climate variability and climate change. We (cf. Mens et al., 2011) are now investigating whether and how the idea of "system robustness" can be applied to flood risk systems, as a further elaboration of "system resilience" (De Bruijn, 2005; De Bruijn et al., 2008). A flood risk system would, according to our preliminary definition, classify as being robust, if it could cope with floods of the full range of plausible magnitudes without the area at stake being affected beyond recovery. This can be achieved by the system having a high degree of resistance - i.e. not responding to floods and/or a high degree of resilience - i.e. being capable to deal with and recover from flooding. Robustness thus comprises a gradual increase of consequence, proportional to an increasing flood magnitude, as well as sufficient recovery capacity and a threshold for recovery that is not likely to be easily exceeded.
Of the strategies we investigated above, we estimate that those with controlled flooding and unbreachable embankments score best on this criterion. After all, they were designed in such a way as to prevent sudden and unexpected breaches with large numbers of fatalities. As they do so with net costs that equal those of the current policy, we plea for a more thorough investigation of such strategies, preferably in the context of the Netherlands' Delta Programme.

\section{Reflection on the approach}

In this paper we advocated an exploratory policy analysis for long-term flood risk management planning, following a procedure proposed by De Bruijn et al. (2008). The case study on the Netherlands' flood risk management policy was undertaken in an attempt to contribute to a better joint framing of the future flood risk management problem and the range of alternatives to be taken into account.

Obviously, an exploratory policy analysis requires making many assumptions and generalizations. Assumptions had to be made about future developments in climate and socio-economy: on the degree of implementation of the current policy (fully effective); on the effectiveness of measures in reducing flood probabilities; inflow volumes; system behaviour along rivers and around lakes; on evacuation percentages; et cetera. Huge leaps were also needed in deciding which measures to put in place for each strategic alternative and where to put them, as well as in calculating the costs of implementing the strategic alternatives. This means that the numbers we present should be considered as gross estimates, reliable only as far as the order of magnitude is concerned, but not as far as exact numbers are concerned. We already emphasized that the numbers are merely indicative. This, however, is inherently connected to such an exploratory analysis, and of course limits its applicability: the approach should only be used for the purpose of selecting attractive strategic alternatives and measures, and does allow abandoning the too expensive, completely ineffective, or otherwise unattractive alternatives and measures. Obviously, our preliminary analysis must be followed by a more thorough full-fledged policy analysis, which can then focus on fewer and more precisely defined alternatives. 
In the Netherlands' case we presented in this paper, the use of scenarios helped us to explore futures beyond what is usually being investigated. Especially the exploration of combined scenarios on climate change and on socio-economic development clarified the true nature of increasing flood risks (Klijn et al., 2012). This helped us to better frame the problem of increasing flood risks and the causes, especially as it revealed the importance of socio-economic developments. The increase of flood risks in the central Rhine River floodplain area would not have been detected otherwise, and its cause - above average development and economic growth - would have remained undiscovered. The scenario exploration also made us question the obvious continuation of the current flood risk management policy, as it clearly revealed how the current policy would affect - or rather, where it would not prevent - the increase of flood risks in the future.

With the improved knowledge on the causes of the increase of flood risks, we were able to select risk-reducing measures that precisely attack these causes, and we could define strategic alternatives that perform better in reducing risks than the current policy at equal or even lower costs. We also experienced that the definition of distinct strategic alternatives allows meaningful assessments and comparison. These have contributed to recommendations on measures and policy strategies that would not have been identified otherwise. The large potential of unbreachable embankments to reduce fatality risks at national level would not have been revealed so clearly, nor would the possible, though small, contribution of spatial planning have been quantified so convincingly. We consider this a significant contribution to a better framing of alternative policies. The definition of distinct alternatives does, however, require that they be designed on the basis of sound guiding principles, as already advocated by De Bruijn et al. (2008). And they should take into account the "principles of comprehensive flood risk management", which call for equal consideration of hazard control and vulnerability reduction (Klijn et al., 2009).

The procedure as such can thus be regarded as useful for achieving a higher degree of convergence in the joint framing of both the problem and the scope of strategic flood risk management alternatives, which deserve investigation. We therefore sincerely hope that our findings will help to frame the research for the Netherlands' Delta Programme. We also recommend our "rapid prototyping" procedure as a useful approach in the framing stage of any policy analysis on behalf of long-term planning for flood risk management in view of global change elsewhere.

Acknowledgements. This paper could be written thanks to a subsidy from the Netherlands' research programme Knowledge for Climate (Theme 1: Climate-proof Flood Risk Management) and is partly based on earlier research within the Integrated Project FLOODsite (EU- 6th Framework Programme, Contract GOCE-CT2004-505420).
Edited by: L. Ferraris

Reviewed by: A. van der Veen and S. Fuchs

\section{References}

Beckers, J. and de Bruijn, K. M.: Analysis of fatality risk Water Safety 21st century, Deltares report 1204144-005, Delft, 2011 (in Dutch).

Bertrand, G., Michalski, A. I., and Pench, L. R.: Scenarios Europe 2010, European Commission Forward Studies Unit, Working Paper 1999, 1999.

Bočkarjova, M., Rietveld, P., and Verhoef, E.: First results immaterial damage valuation: VOSL in flood risk context - a stated preference study, Report, department of Spatial Economics, Free University, Amsterdam, 2009.

De Bruijn, K. M.: Resilience and flood risk management: a systems approach applied to lowland rivers, Delft Hydraulics Series 6, Delft Hydraulics, Delft, 2005

De Bruijn, K. M. and Klijn, F.: Risky places in the Netherlands: a first approximation for floods, J. Flood Risk Manag., 2, 58-67, 2009.

De Bruijn, K. M. and van der Doef, M.: Consequences of flooding; information in support of the project Water Safety 21st century, Deltares report 1204144-004, Delft, 2011 (in Dutch).

De Bruijn, K. M., Klijn, F., McGahey, C., Mens, M., and Wolfert, H.: Long-term strategies for flood risk management: scenario definition and strategy design, FLOODsite report T14-08-01, 2008.

Delta Committee: Working together with water. A vital country builds its future, The Hague, 2008 (in Dutch).

Eijgenraam, C. J. J.: Optimal safety standards for dike-ring areas, CPB discussion paper 62, CPB, The Hague, 2006.

FLOODsite: Flood risk assessment and flood risk management, An introduction and guidance based on experiences and findings of FLOODsite (an EU-funded Integrated Project), Deltares | Delft Hydraulics, Delft, The Netherlands, ISBN 97890814067 10,140 pp., e-publication, availabe at: http://www.floodsite.net, 2009.

Haasnoot, M., Middelkoop, H., Van Beek, E., and Van Deursen, W. P. A.: A Method to Develop Sustainable Water Management Strategies for an Uncertain Future, Sustainable Development 19, 369-381, doi:10.1002/sd.438, 2011.

Hutter, G., McFadden, L., Penning-Rowsell, E., Tapsell, S., and Borga, M.: Strategies for Pre-Flood Risk Management; case studies and recommendations, FLOODsite report T13-07-04, available at: http://www.floodsite.net, 2007.

Jonkman, S. N.: Loss of life estimation in flood risk assessment, Theory and applications, Delft University of Technology, Delft, 2007.

Kind, J.: Flood risk 21st century: preliminary cost benefit analysis, RWS-Waterdienst, report WD 2008.044, Lelystad, 2008 (in Dutch).

Kind, J.: Societal cost benefit analysis Water Safety 21 st century, Deltares report 1204144-006, Utrecht, 2011 (in Dutch).

Klijn, F., and De Grave, P.: Setting limits to flood consequences? A reflection on the outcomes of the compartmentalization study, Deltares-report T2513.50, Delft, 2008 (in Dutch).

Klijn, F., van der Klis, H., Stijnen, J., de Bruijn, K. M., and Kok, M.: Flood risk in dike-ring areas in the Netherlands; line of reasoning 
and expert judgments, Delft Hydraulics report Q3503.10, Delft, 2004a (in Dutch).

Klijn, F., Van Buuren, M., and Van Rooij, S. A. M.: Flood risk management strategies for an uncertain future: living with Rhine River floods in the Netherlands? Ambio 33, 141-147, 2004b.

Klijn, F., Baan, P., de Bruijn, K. M., and Kwadijk, J.: Flood risks in the Netherlands in a changing climate; expectations, estimates and calculations for the 2nd Sustainability Outlook for the Netherlands, Delft Hydraulics report Q4290, Delft, 2007 (in Dutch).

Klijn, F., Samuels, P., and van Os, A.: Towards flood risk management in the EU: State of affairs with examples from various European countries, J. River Basin Manag., 6, 307-321, 2008.

Klijn, F., Kwadijk, J., De Bruijn, K. M., and Hunink, J.: Flood risks and drought risks in a changing climate; survey of pathways to climate-change proofing the Netherlands, Deltares report 1002565, Delft, 2010 (in Dutch).

Klijn, F., Asselman, N. E. M., and van der Most, H.: Compartmentalization: flood consequence reduction by splitting-up large polder areas, J. Flood Risk Manag., 3, 3-17, doi:10.1111/j.1753318X.2009.01047.x, 2010.

Klijn, F., de Bruijn, K. M., Knoop, J., and Kwadijk, J.: Assessment of the Netherlands' flood risk management policy under global change, Ambio, 41, 180-192, doi:10.1007/s13280-011-0193-x, 2012.

Mens, M. J. P., Klijn, F., de Bruijn, K. M., and van Beek, E.: The meaning of system robustness for flood risk management, Environ. Sci. Policy, 14, 1121-1131, 2011.

Messner, F., Penning-Rowsell, E., Green, C., Meyer, V., Tunstall, S., and van der Veen, A.: Evaluating flood damages: guidance and recommendations on principles and methods, FLOODsite report T09-06-01, available at: www.floodsite.net, 2007.

Ministry of Transport, Public Works and Water Management: National Water Plan 2009-2015, 2009 (in Dutch).

Popper, S. W., Lempert, R. J., and Bankes, S. C.: Shaping the Future, Scientific American, April 2005, 66-71, 2005.

Pulles, J. W.: Policy analysis of the water management of the Netherlands, The Hague, 1985.

Samuels, P., Klijn, F., and Dijkman, J. P. M.: An analysis of the current practice of policies on river flood risk management in different countries, Irrig. Drain., 55, 141-150, 2006.

Schanze, J.: Flood Risk Management - A Basic Framework, in: Flood Risk Management; Hazards, Vulnerability and Mitigation Measures, edited by: Schanze, J., Zeman, E., and Marsalek, J., NATO Science Series IV, Earth and Environmental Sciences, 67, Springer, Dordrecht, 1-20, 2006.

Silva, W. and van Velzen, E.: The embankment of the future? Quick-scan unbreachable embankments, Deltares report Q4558.32, 2008 (in Dutch).
Stijnen, J.: Unbreachable embankments, Memo flooding, HKV memorandum PR 1410.10, Lelystad (appendix with Silva and Van Velzen, 2008), 2008 (in Dutch).

Ten Brinke, W. B. M. and Bannink, B. A.: Flood risk: an evaluation of the flood risk management policy, RIVM- MNP, Bilthoven, 2005 (in Dutch).

Ten Brinke, W. B. M., Bannink, B. A., and Ligtvoet, W.: The evaluation of flood risk policy in the Netherlands, Proceedings of the Institution of Civil Eng. Water Manage., 162, 181-188, 2008.

Thissen, W. A. H.: From SEA to Integrated Assessment: a Policy Analysis Perspective, Magazine of the Institute of Environmental Assessment and the Environmental Auditors Registration Association, 3, 3, Lincoln, UK, 25-26, ISSN 1351-0738, 1997.

Thompson, M.: Understanding Environmental Values: a Cultural Theory Approach, Event paper, Carnegie Council on Ethics and International Affairs, available at: www.carnegiecouncil.org, last access: September 2010, 2002.

UKCIP02: Climate Change Scenarios for the United Kingdom: The UKCIP02 Scientific Report, Tyndall Centre for Climate Change Research, School of Environmental Sciences, University of East Anglia, Norwich, UK, 120 pp., 2002.

UNEP and RIVM: Four scenarios for Europe, Based on UNEP's third Global Environment Outlook, UNEP/DEIA andEW/TR.0310 and RIVM 402001021, 2003.

Van Asselt, M. B. A., Middelkoop, H., van 't Klooster, S. A., van Deursen, W. P. A., Haasnoot, M., Kwadijk, J. C. J., Buiteveld, H., Können, G. P., Rotmans, J., van Gemert, N., and Valkering, P.: Integrated water management strategies for the rhine and meuse basins in a changing environment, Dutch National Research Programme on Climate Change, project 958273, IRMA-SPONGE project 3/NL/1/164/99 15183 01, 2001.

Van Mierlo, M. C. L. M., Vrouwenvelder, A. C. W. M., Calle, E. O. F., Vrijling, J. K., Jonkman, S. N., de Bruijn, K. M., and Weerts, A. H.: Assessment of flood risk accounting for river system behaviour, J. Flood Risk Manage., 5, 93-104, 2007.

Veeneklaas, F. R. and van den Berg, L. M.: Scenario building: art or craft or just a fashionable whim?, in: Scenario Studies for the Rural Environment: Selected and edited Proceedings of the Symposium Scenario Studies for the Rural Environment, edited by: Schoute, J. F. Th., Finke, P. A., Veeneklaas, F. R., and Wolfert, H. P., Wageningen, The Netherlands, 12-15 September 1994, Kluwer Academic Publishers, Dordrecht, The Netherlands, 11$13,1995$.

Walker, W. E.: The use of screening in policy analysis, Manage. Sci., 32, 389-402, 1986.

Walker, W. E.: Policy Analysis: A Systematic Approach to Supporting Policymaking in the Public Sector, J. Multi-Criteria Decision Analysis, 9, 11-27, 2000. 